\title{
Conservation implications of source-sink dynamics within populations of endangered Maculinea butterflies
}

\author{
Natalia Timus $^{1} \cdot$ Zsolt Czekes $^{2,3} \cdot$ Laszlo Rákosy $^{1} \cdot$ Piotr Nowicki $^{4}$ DD
}

Received: 19 April 2016 / Accepted: 19 August 2016 / Published online: 30 August 2016

(C) The Author(s) 2016. This article is published with open access at Springerlink.com

\begin{abstract}
Conservation programmes are often based on snapshot information on animal abundance. However, land fragments with high numbers of individuals do not necessarily represent their natal areas, which are crucial for species persistence. A classic example of the above principle are source-sink systems, in which excess individuals emigrate from source areas during their lifetime and gather in sink areas. We demonstrated the existence of source-sink dynamics in two species of endangered Maculinea (=Phengaris) butterflies. Sympatrically occurring $M$. nausithous and $M$. teleius were investigated with mark-recapture sampling during the entire flight period. In the first half of the season a great majority of butterflies were captured within the relatively small central part of the site, while later their numbers became similar between the site centre and its peripheries. The analysis of movements indicated that most individuals captured in the peripheral zone eclosed in the central zone. Moreover, the timing of the sharp increase in movements from the site centre to its peripheries corresponded well with the period when the number of eggs laid in the former area reached carrying capacity, defined by the number of the Sanguisorba officinalis foodplant
\end{abstract}

Piotr Nowicki

piotr.nowicki@uj.edu.pl

1 Department of Taxonomy and Ecology, Babeș-Bolyai University, Clinicilor 5-7, Cluj-Napoca, Romania

2 Hungarian Department of Biology and Ecology, BabeșBolyai University, Clinicilor 5-7, Cluj-Napoca, Romania

3 Interdisciplinary Research Institute on Bio-Nano-Sciences, Treboniu Laurian 42, Cluj-Napoca, Romania

4 Institute of Environmental Sciences, Jagiellonian University, Gronostajowa 7, 30-387 Kraków, Poland flowerheads available for oviposition. Within the peripheral zone the foodplant availability greatly exceeded the egg load, but in contrast the abundance of host ants (i.e. the other essential resource) was low, which presumably results in low Maculinea larval survival there. Our findings imply that setting conservation priorities over different land fragments should take into account dispersion of individuals among them.

Keywords Mark-recapture - Population survey · Resource availability $\cdot$ Source-sink system $\cdot$ Species conservation

\section{Introduction}

Source-sink dynamics is a phenomenon of high importance for population ecology (Pulliam 1988; Pulliam and Danielson 1991). Populations with intrinsic growth rate exceeding one may either increase in size or, in the more frequent case when the carrying capacity of their habitats limits population increase, they produce surplus individuals, which tend to emigrate from their natal sites (Diffendorfer 1998). Therefore, such populations become sources of immigrants into sink populations with intrinsic growth rate below one (Pulliam 1988; Tittler et al. 2006). The continuous influx of immigrants provides rescue effects for declining populations, supporting their persistence (Hanski et al. 1996).

The existence of source and sink populations has serious consequences for species conservation. Its most important implication is the fact that only source populations guarantee long-term species survival (Dias 1996). In turn, sink populations are in principle not necessary for species survival. Actually, their existence may occasionally be harmful in this respect, as exemplified by the case of so-called 
attractive sinks (Delibes et al. 2001; Battin 2004). These represent areas that strongly attract immigrants, typically through the high availability of certain resources required by the species, but they are short in other crucial resources, for instance those which are essential for offspring. In such areas the chances of successful reproduction are precluded or at least substantially reduced, and in this way attractive sinks loose the reproductive potential of the immigrants, which could otherwise enhance the viability of other populations.

Consequently, conservation efforts should be focused on source populations and not on the sink ones. However, when setting conservation priorities most programmes rely on snapshot information on the occurrence or abundance of certain target species rather than on the thorough understanding of their population dynamics, and thus distinguishing between sources and sinks is difficult in practice (Dias 1996; Runge et al. 2006). This is particularly true in the case when individuals are more abundant or just more conspicuous in their sink habitats.

Most empirical studies have so far investigated sourcesink systems at a relatively large scale of entire metapopulations (Thomas et al. 1996; Boughton 1999; Tittler et al. 2006). Nevertheless, source-sink dynamics is similarly likely to occur at a much smaller spatial scales, namely within habitat patches inhabited by single local populations. This is because resource availability within habitat patches is typically not uniform, but rather highly heterogeneous. Consequently, certain patch fragments are rich in resources and they are able to produce net excess of individuals, which can subsequently move to the fragments of low quality. The aim of the present study was to demonstrate the existence of a within-patch source-sink system in endangered Maculinea (=Phengaris) butterflies. For this purpose we used the data provided by an intensive survey of $M$. nausithous and $M$. teleius, occurring sympatrically at a highly heterogeneous site in central Transylvania, Romania. We also discuss the implications of such a small scale source-sink dynamics for the conservation of the two focal species.

\section{Materials and methods}

\section{Study system}

Butterflies of the genus Maculinea are regarded as flagships of insect conservation in Europe and useful indicators of grassland biodiversity (Maes and van Dyck 2005; Settele et al. 2005). They are highly specialised myrmecophilous species, requiring two essential resources to complete their life cycle. These comprise specific foodplants, on which Maculinea larvae feed in their initial stages, and specific host ants of the genus Myrmica, in the colonies of which
Maculinea larvae act as social parasites and complete their development (Thomas 1995; Witek et al. 2010). Foodplants are typically patchily distributed and thus their occurrence defines the spatial limits of Maculinea habitats (Nowicki et al. 2007; Nowicki and Vrabec 2011). In turn, Myrmica host ants are usually widespread but their abundance varies greatly and it shapes the carrying capacity of Maculinea habitat patches (Hochberg et al. 1994; Nowicki et al. 2009).

The study was conducted at the Fanatul Domnesc site near the village of Rascruci in central Transylvania, Romania $\left(46.92^{\circ} \mathrm{N}, 23.73^{\circ} \mathrm{E} ; 410-460 \mathrm{~m}\right.$ a.s.1.). The site is a mesohygrophilous meadow with a relatively large patch of Sanguisorba officinalis, which is the exclusive larval foodplant of both M. nausithous and M. teleius, as well as the primary nectar source for their adults (Elmes and Thomas 1992; Thomas 1995). The central part of the patch (2.37 ha in area) comprises a boggy depression with Molinion caeruleae Koch 1926, whereas its peripheral fragments (12.89 ha in area) are dryer and covered with Cirsio-Brachypodion pinnati Hadač et Klika ex Klika 1951 (Stoianov et al. 2012; see this reference for further information about the site).

The peculiarity of the Fanatul Domnesc site is the fairly low density of $S$. officinalis (see the "Results"). While at most other sites with M. nausithous and/or M. teleius, the availability of the $S$. officinalis flowerheads, in which larvae of both species feed for the initial 3-4 weeks, usually exceed the population requirements by at least an order of magnitude (Nowicki et al. 2007, 2009), this is clearly not the case at Fanatul Domnesc. Consequently, unlike at other sites, the foodplant availability can be considered a limiting factor for the focal populations of both Maculinea species. The other constraint for population dynamics is the availability of host ant nests. Earlier field studies have revealed that $M$. nausithous and M. teleius share the same local host ant in the region, namely Myrmica scabrinodis (Tartally and Varga 2008; Tartally et al. 2008). In the case of the former butterfly, which within its European distribution range is mostly associated with Myrmica rubra, such a host species is unusual, although not exceptional (cf. Munguira and Martin 1999; Witek et al. 2008), but it is typical for the subspecies $M$. nausithous kijevensis occuring in Transylvania (Rákosy et al. 2010).

Maculinea populations at Fanatul Domnesc are relatively isolated. The only other nearby locality inhabited by M. nausithous and M. teleius is Fanatul Satesc, situated ca. $1 \mathrm{~km}$ away. Such a separation distance is several times longer than typical movement distances for both species in grassland landscapes (Nowicki et al. 2014). Furthermore, this other locality is much smaller and few adult butterflies have been observed there in recent years (authors' unpubl. data). Consequently, a considerable exchange of individuals between our focal site and other populations in the region is unlikely; in fact we recorded merely two cases of inter-patch 
movements of Maculinea butterflies (one for each species) between Fanatul Domnesc and Fanatul Satesc.

\section{Field surveys}

In summer 2009 low intensity mark-recapture sampling of M. nausithous and M. teleius was conducted at Fanatul Domnesc to provide general information about the size of their populations (Vodă et al. 2010). This preliminary study suggested a somewhat surprising pattern: butterflies tended to concentrate in the central part of the meadow in July, roughly corresponding to the first half of the season, whereas in August their distribution was far more dispersed all over the site. However, the data gathered were not good enough to allow a detailed analysis of the pattern observed. Consequently, in order to investigate the pattern we decided to launch a more intensive mark-recapture survey in 2010.

The survey was conducted between 12 July and 27 August, thus spanning the entire flight period of both investigated species. Butterflies were captured between 9:00 and 17:00 on roughly every third day (weather allowing), and the sampling intensity was kept fairly uniform across the whole site. Captured individuals were marked with consecutive numbers written on the underside of their hind wings using permanent sharp-tipped markers, and immediately released at the spot. In each case we determined the butterfly sex and recorded the position of its capture with GPS units Garmin GPSMAP 60CSx (Olathe, USA).

In the same year we assessed the abundance of foodplants and host ants at Fanatul Domnesc. For the purpose of foodplant surveys, we established $1 \mathrm{~m}^{2}$ square sampling plots, which were randomly distributed all over the site, although with stratification so as to ensure representative numbers of sampling plots within both the central part as well as the peripheral fragments of the site (63 and 319 plots respectively). In each plot we counted the number of $S$. officinalis shoots and flowerheads on each shoot. When estimating the availability of flowerheads for Maculinea, we assumed that only about one-third of them were in the proper phenological state for oviposition during the flight period of these butterflies (Figurny and Woyciechowski 1998).

Ant surveys were conducted in circular plots of 4-m diameter ( 32 within the central part and 84 within the peripheral fragments of Fanatul Domnesc). These plots were thoroughly searched for ant nests between 28 June and 20 July 2010. From each nest we took ca. 20 workers for species identification. In addition, we collected foraging ant workers using pitfall traps. We used standard plastic cups of $75 \mathrm{~mm}$ diameter, half-filled with ethylene glycol. One pitfall trap was placed in the centre of each plot and left for 10 days from 16 to 26 September 2010. Since some pitfall traps were destroyed by grazing animals, the sample size was reduced to 28 and 40 traps within respectively the central and peripheral part of the site. Ant species identification was conducted with the help of the keys by Radchenko and Elmes (2010), Czechowski et al. (2012), and Czekes et al. (2012).

\section{Analysis}

Each butterfly capture was classified as occurring either in the central part of Fanatul Domnesc or in its peripheral fragments. Subsequently, the mark-recapture data gathered were analysed with MARK 8.0 software (White and Burnham 1999) using the multi-state recapture models of Brownie et al. (1993). The analyses were conducted separately for M. nausithous and M. teleius, with two different zones of the site (central part and peripheries) adopted as 'states'. The model allows the estimation of capture probability $(p)$ and survival $(\phi)$ within each state as well as the probability of transition between the states $(\psi)$, i.e. in our case the probability of movement between the two defined zones of Fanatul Domnesc. We tested model variants with different patterns in all the above parameters including constant value denoted as (.), intersexual difference $(s)$, temporal variation $(t)$, additive effects of intersexual difference and temporal variation $(s+t)$ as well as their independent effects $\left(s^{*} t\right)$. The performance of specific models was compared using the Akaike Information Criterion corrected for small sample size $\left(\mathrm{AIC}_{\mathrm{c}}\right.$ ) (Akaike 1973; Hurvich and Tsai 1989). While the lowest $\mathrm{AIC}_{\mathrm{c}}$ value indicates the best performing model, all the models with the $\mathrm{AIC}_{\mathrm{c}}$ value exceeding the lowest one by less than 2 should be regarded as supported by the data (Burnham and Anderson 2001). Since for each species there were several supported models performing similarly well, we decided to rely on the parameter values calculated as weighted means for all the supported models using their Akaike weights. Akaike weight can be interpreted as the probability of a particular model being the most appropriate one (Burnham and Anderson 2001).

Based on the Brownie model parameters obtained with MARK program $(p, \phi, \psi)$, we estimated further parameters describing within-season dynamics of the investigated populations. Daily numbers of butterflies present in both zones ( $\mathrm{C}=$ patch centre, $\mathrm{M}=$ patch margins $)$ on day $i$ were calculated as:

$N_{\mathrm{C}, i}=n_{\mathrm{C}, i} / p_{\mathrm{C}, i}$ and $N_{\mathrm{M}, i}=n_{\mathrm{M}, i} / p_{\mathrm{M}, i}$,

where $n_{C, i}$ and $n_{M, i}$ represent the numbers of captured individuals, which are known from capture records. The Brownie model is based on the assumption of equal capture probability for all individuals, which may be problematic to meet for butterflies, in which intersexual differences in catchability have often been reported (Nowicki et al. 2008). However, we avoided this problem by relying on capture 
probability estimates derived separately for both sexes (see below). Subsequently, the numbers of butterflies moving from one zone to the other within the interval between sampling days $i$ and $i+1$ were derived as:

$$
M_{\mathrm{C} \rightarrow \mathrm{M}, i}=N_{\mathrm{C}, i} \cdot \phi_{\mathrm{C}, i} \cdot \psi_{\mathrm{C} \rightarrow \mathrm{M}, i} \text { and } M_{\mathrm{M} \rightarrow \mathrm{C}, i}=N_{\mathrm{M}, i} \cdot \phi_{\mathrm{M}, i} \cdot \psi_{\mathrm{M} \rightarrow \mathrm{C}, i}
$$

Finally, it was also possible to estimate the demographic recruitments within this interval, i.e. in our case the numbers of butterflies eclosing in each zone, as the difference between the butterfly numbers on day $i+1$ and the sum of survivors from day $i$ and immigrants from the other zone:

$B_{\mathrm{C}, i}=N_{\mathrm{C}, i+1}-\left[N_{\mathrm{C}, i} \cdot \phi_{\mathrm{C}, i} \cdot\left(1-\psi_{\mathrm{C} \rightarrow \mathrm{M}, i}\right)+M_{\mathrm{M} \rightarrow \mathrm{C}, i}\right]$

and similarly in the case of $B_{\mathrm{M}, i}$

All the above population parameters were estimated separately for both sexes, and then summed up, because the model selection routine based on $\mathrm{AIC}_{\mathrm{c}}$ indicated intersexual differences in several Brownie model parameters. It is worth noting that the sum of recruitments throughout the flight period constitutes the total number of butterflies originating from a particular zone $\left(N_{\text {total }}\right)$, and the total number of individuals moving from one to the other $\left(M_{\text {total }}\right)$ can be obtained in a similar way.

We also assessed the number of eggs present on each sampling day through multiplying the numbers of females flying prior to the date by 75 eggs per female. The above figure represents the average fecundity in closely related $M$. arion (Thomas et al. 1998a); it is also in good agreement with our own rough estimates for $M$. nausithous and M. teleius obtained in Poland (ca. 80 eggs per female; P. Nowicki unpubl. data).
We compared the overall egg load estimated in this way with the number of $S$. officinalis flowerheads available in the central and marginal zone, calculated as the product of zone area, flowerhead density, and the proportion of flowerheads in the proper phenological state for oviposition, assumed as onethird after Figurny and Woyciechowski (1998).

\section{Results}

During the entire season we recorded 1350 captures of 842 M. nausithous adults, and 392 captures of 258 M. teleius adults. In the first half of the season, namely in July, the captures of both species were made predominantly within the central part of the investigated site, whereas in August their distribution was more balanced, with similar numbers of captures occurring in both the central part as well as the marginal fragments (Fig. 1).

The multi-model selection routine based on the Akaike Information Criterion revealed that several multi-state recapture models were well supported by the data collected for each species (Table 1). Nevertheless, the structure of these models differed only with regard to survival rate and capture probability. At the same time all the models indicated an identical pattern in the butterfly transition probabilities between the two zones defined, namely intersexual differences and additionally the existence of temporal variation in the probability of moving from the central to the marginal zone of Fanatul Domnesc but not the other way round (Table 1). Daily survival was relatively high in both species, with the values given in Table 2 corresponding to adult life span of approximately 4 to 8 days. a

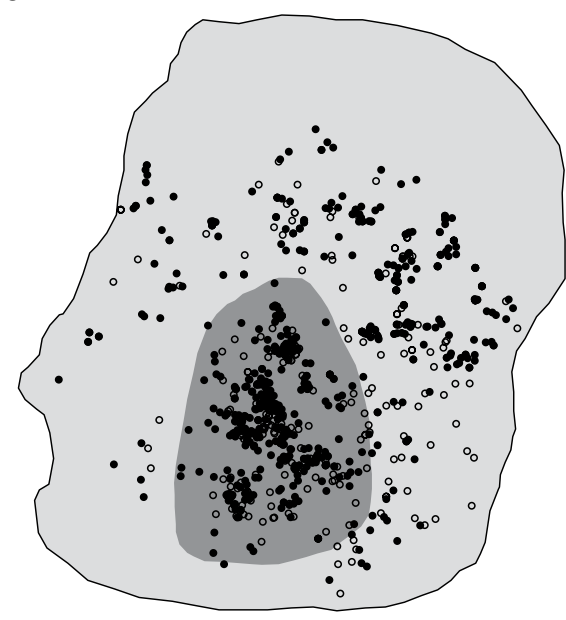

b

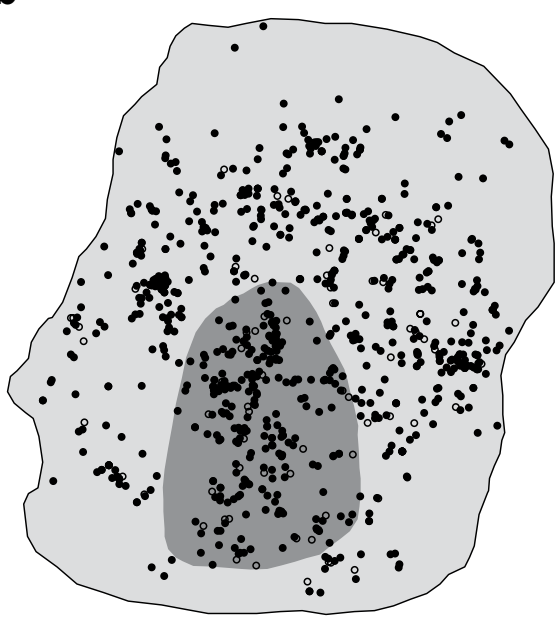

$100 \mathrm{~m}$

Fig. 1 Distribution of capture points of M. nausithous (solid dots) and M. teleius (empty dots) within the central part (dark grey area) and marginal fragments (light grey area) of the studied site in July (a) and
August (b). It should be noted that the number of capture points within the former area is visually underestimated, because in many cases several individuals were captured in exactly the same locations 
Table 1 Performance of the supported multi-state recapture models for the two investigated Maculinea species, as indicated by their Akaike Information Criterion corrected for small sample size $\left(\mathrm{AIC}_{\mathrm{c}}\right)$, its difference from the value of the best performing model $\left(\Delta \mathrm{AIC}_{\mathrm{c}}\right)$, and Akaike weight $(w)$

\begin{tabular}{lllll}
\hline Model type & No. of parameters & $\mathrm{AIC}_{\mathrm{c}}$ & $\Delta \mathrm{AIC}_{\mathrm{c}}$ & $w$ \\
\hline M. nausithous & & & & \\
$\phi_{\mathrm{C}}(.) \phi_{\mathrm{M}}(s) p_{\mathrm{C}}(t) p_{\mathrm{M}}(.) \psi_{C \rightarrow M}(s+t) \psi_{M \rightarrow C}(s)$ & 35 & 2305.14 & 0 & 0.270 \\
$\phi_{\mathrm{C}}(s) \phi_{\mathrm{M}}(.) p_{\mathrm{C}}(t) p_{\mathrm{M}}(.) \psi_{C \rightarrow M}(s+t) \psi_{M \rightarrow C}(s)$ & 35 & 2305.76 & 0.62 & 0.198 \\
$\phi_{\mathrm{C}}(s) \phi_{\mathrm{M}}(s) p_{\mathrm{C}}(t) p_{\mathrm{M}}(.) \psi_{C \rightarrow M}(s+t) \psi_{M \rightarrow C}(s)$ & 36 & 2306.08 & 0.94 & 0.169 \\
$\phi_{\mathrm{C}}(.) \phi_{\mathrm{M}}(s) p_{\mathrm{C}}\left(s^{*} t\right) p_{\mathrm{M}}(.) \psi_{C \rightarrow M}(s+t) \psi_{M \rightarrow C}(s)$ & 49 & 2306.41 & 1.28 & 0.143 \\
$\phi_{\mathrm{C}}(.) \phi_{\mathrm{M}}(s) p_{\mathrm{C}}(t) p_{\mathrm{M}}(s) \psi_{C \rightarrow M}(s+t) \psi_{M \rightarrow C}(s)$ & 36 & 2306.85 & 1.71 & 0.115 \\
$\phi_{\mathrm{C}}(.) \phi_{\mathrm{M}}(.) p_{\mathrm{C}}(t) p_{\mathrm{M}}(s) \psi_{C \rightarrow M}(s+t) \psi_{M \rightarrow C}(s)$ & 35 & 2307.03 & 1.89 & 0.105 \\
$M_{\text {. teleius }}$ & & & & \\
$\phi_{\mathrm{C}}(.) \phi_{\mathrm{M}}(.) p_{\mathrm{C}}(.) p_{\mathrm{M}}(.) \psi_{C \rightarrow M}(s+t) \psi_{M \rightarrow C}(s)$ & 17 & 590.63 & 0 & 0.224 \\
$\phi_{\mathrm{C}}(s) \phi_{\mathrm{M}}(.) p_{\mathrm{C}}(.) p_{\mathrm{M}}(.) \psi_{C \rightarrow M}(s+t) \psi_{M \rightarrow C}(s)$ & 18 & 591.01 & 0.38 & 0.185 \\
$\phi_{\mathrm{C}}(.) \phi_{\mathrm{M}}(s) p_{\mathrm{C}}(.) p_{\mathrm{M}}(.) \psi_{C \rightarrow M}(s+t) \psi_{M \rightarrow C}(s)$ & 18 & 591.47 & 0.83 & 0.148 \\
$\phi_{\mathrm{C}}(.) \phi_{\mathrm{M}}(.) p_{\mathrm{C}}(s) p_{\mathrm{M}}(.) \psi_{C \rightarrow M}(s+t) \psi_{M \rightarrow C}(s)$ & 18 & 591.57 & 0.94 & 0.140 \\
$\phi_{\mathrm{C}}(.) \phi_{\mathrm{M}}(.) p_{\mathrm{C}}(.) p_{\mathrm{M}}(s) \psi_{C \rightarrow M}(s+t) \psi_{M \rightarrow C}(s)$ & 18 & 591.72 & 1.09 & 0.130 \\
$\phi_{\mathrm{C}}(s) \phi_{\mathrm{M}}(.) p_{\mathrm{C}}(s) p_{\mathrm{M}}(.) \psi_{C \rightarrow M}(s+t) \psi_{M \rightarrow C}(s)$ & 19 & 592.54 & 1.91 & 0.086 \\
$\phi_{\mathrm{C}}(s) \phi_{\mathrm{M}}(s) p_{\mathrm{C}}(.) p_{\mathrm{M}}(.) \psi_{C \rightarrow M}(s+t) \psi_{M \rightarrow C}(s)$ & 19 & 1.88 & 0.088 \\
\hline
\end{tabular}

The notation of the models follows the standard system (see the "Analysis" section of the text for a detailed explanation), with subscripts $\mathrm{C}$ and $\mathrm{M}$ representing respectively the central and marginal part of the studied site

Table 2 Weighted mean parameter estimates $( \pm S E)$ of the supported multi-state recapture models for the two investigated Maculinea species in the central (C) and marginal part (M) of the studied site

\begin{tabular}{|c|c|c|c|c|c|c|c|}
\hline \multirow[t]{2}{*}{ Species } & \multirow[t]{2}{*}{ Sex } & \multicolumn{2}{|l|}{ Survival rate } & \multicolumn{2}{|c|}{ Capture probability } & \multicolumn{2}{|c|}{ Transition probability } \\
\hline & & $\mathrm{C}$ & M & $\mathrm{C}$ & M & $\mathrm{C} \rightarrow \mathrm{M}$ & $\mathrm{M} \rightarrow \mathrm{C}$ \\
\hline \multirow[t]{2}{*}{ M. nausithous } & Males & $0.89 \pm 0.01$ & $0.82 \pm 0.01$ & $0.44 \pm 0.06^{*}$ & $0.47 \pm 0.06$ & $0.38 \pm 0.06^{*}$ & $0.21 \pm 0.05$ \\
\hline & Females & $0.84 \pm 0.03$ & $0.77 \pm 0.02$ & $0.22 \pm 0.06^{*}$ & $0.41 \pm 0.06$ & $0.91 \pm 0.07 *$ & $0.44 \pm 0.08$ \\
\hline \multirow[t]{2}{*}{ M. teleius } & Males & $0.87 \pm 0.04$ & $0.79 \pm 0.03$ & $0.47 \pm 0.16$ & $0.40 \pm 0.14$ & $0.68 \pm 0.15^{*}$ & $0.03 \pm 0.03$ \\
\hline & Females & $0.83 \pm 0.04$ & $0.78 \pm 0.03$ & $0.30 \pm 0.09$ & $0.49 \pm 0.17$ & $0.80 \pm 0.10 *$ & $0.13 \pm 0.07$ \\
\hline
\end{tabular}

The parameter values marked with asterisks are shown for the sake of consistency, even though the supported models revealed temporal variation in these parameters (see Table 1). In such cases the means were first estimated separately for each supported model using the numbers of individuals captured per capture day as weights, and subsequently they were weighted across the supported models based on their Akaike weights

Besides, the survival was consistently (although rather slightly) higher within the central zone as well as in males as compared with females. Capture probabilities reached a noteworthy level of $40-50 \%$ in most cases (Table 2), which resulted in fairly good precision of butterfly abundance estimates.

The within-season population dynamics in both $\mathrm{Macu}$ linea species reflected very well the aforementioned change in the spatial distribution of capture points with the season progression. In July the daily numbers of butterflies present within the central part of Fanatul Domnesc greatly exceeded those estimated for the site peripheries, but in the following month the difference in the numbers of individuals flying within the two zones was rather small in the case of $M$. nausithous or hardly existent at all in the case of M. teleius (Fig. 2). The seasonal population size for the entire site was assessed at $2131 \mathrm{M}$. nausithous adults and $593 \mathrm{M}$. teleius adults, the great majority (ca. $80 \%$ regardless of the species) of which eclosed within the central zone (Table 3 ).

In concordance with the above proportion we found that host ant availability was considerably poorer within the site margins. The density of My. scabrinodis nests in this part was about four times lower than in the central zone, and in the case of the numbers of foragers recorded in pitfall traps this disproportion rose to almost an order of magnitude (Table 3). This indicates small sizes of host ant colonies, many of which may thus be too small to support the full development of Maculinea larvae. In contrast, there was hardly any difference in the densities of the other essential resource, i.e. the flowerheads of $S$. officinalis foodplants, between the two defined zones of the Fanatul Domnesc site (Table 3). Nevertheless, the much larger area of the peripheral fragments made the difference, and hence the overall availability of the 

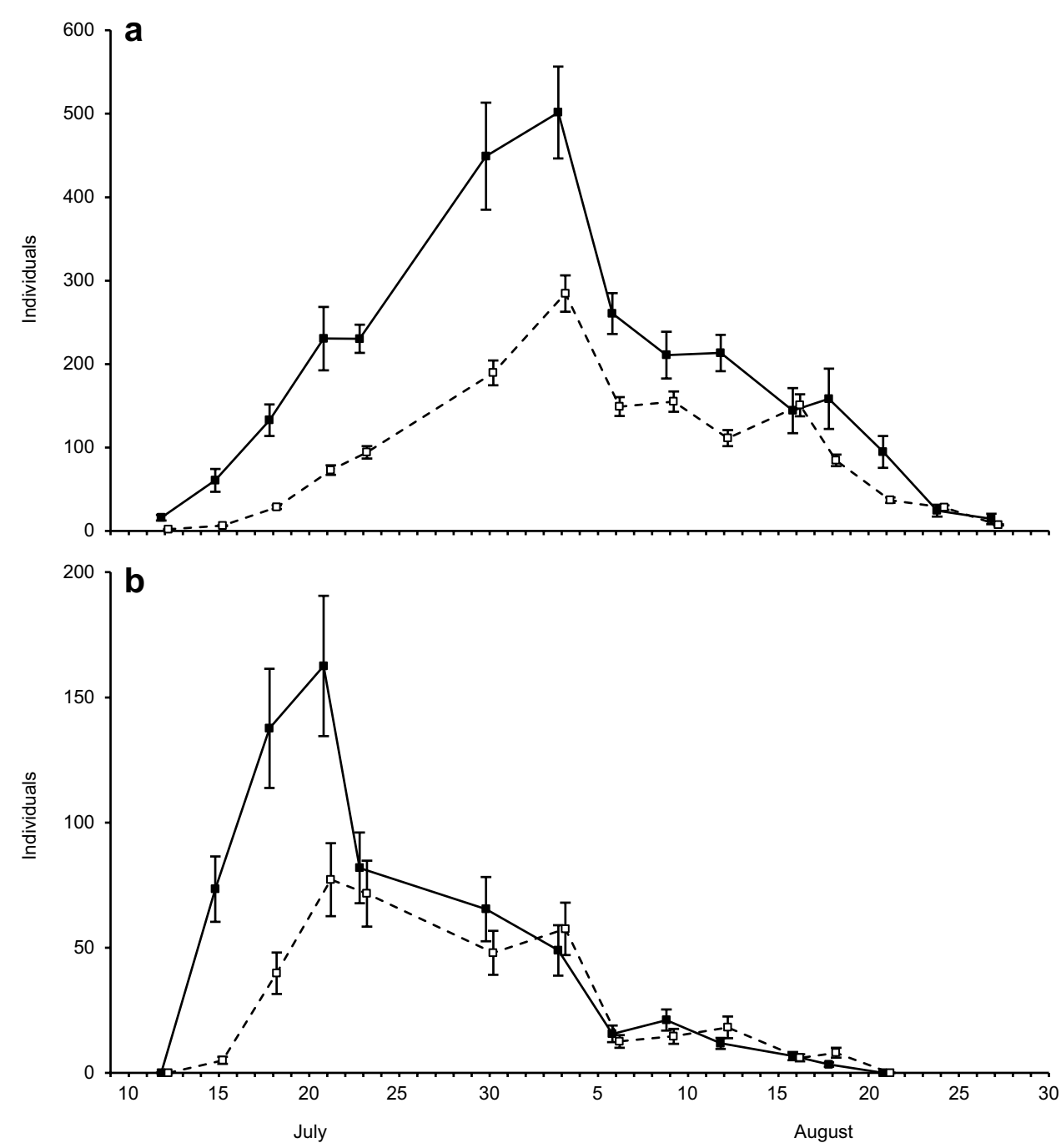

Fig. 2 Within-season dynamics of the daily numbers $( \pm S E)$ of $M$. nausithous $(\mathbf{a})$ and M. teleius $(\mathbf{b})$ within the central part (solid squares, solid line) and marginal fragments (empty squares, broken line) of the studied site

Table 3 Numbers of eclosing adult butterflies of the two investigated Maculinea species and the availability of their crucial resources within the central and marginal part of the studied site

\begin{tabular}{lcc}
\hline Parameter & Central part & Marginal part \\
\hline M. nausithous adults & $1715 \pm 376$ & $416 \pm 92$ \\
M. teleius adults & $470 \pm 130$ & $123 \pm 40$ \\
S. officinalis & & \\
$\quad$ Flowerhead density per $\mathrm{m}^{2}$ & $6.88 \pm 2.09$ & $7.44 \pm 1.63$ \\
$\quad$ Total number of flowerheads & $163 \pm 50$ & $959 \pm 210$ \\
$\quad$ (in thousands) & & \\
My. scabrinodis & & \\
Nest density per $\mathrm{m}^{2}$ & $0.122 \pm 0.027$ & $0.034 \pm 0.009$ \\
$\quad$ Workers per pitfall trap & $4.57 \pm 1.56$ & $0.60 \pm 0.15$ \\
\hline
\end{tabular}

All the estimated values are presented with their $S E$ s foodplant flowerheads was far greater there. Consequently, the estimated number of eggs laid by both species within the central part of the site was likely to exceed the number of flowerheads available at the beginning of August (Fig. 3c), whereas in the site peripheries the flowerhead availability surpassed the egg load by over an order of magnitude.

The moving between the two defined zones was invariably more frequent in females. The probability of transition from the marginal to central zone reached a moderate level only in M. nausithous females, otherwise being relatively low (Table 2). In turn, the probability of moving in the opposite direction showed strong temporal variation (Fig. 3a, b). It was close to zero at the beginning of flight period, and then rose to a very high level ( $>80 \%$ in females). Interestingly, the timing of this sharp increase in frequency of movements from the 

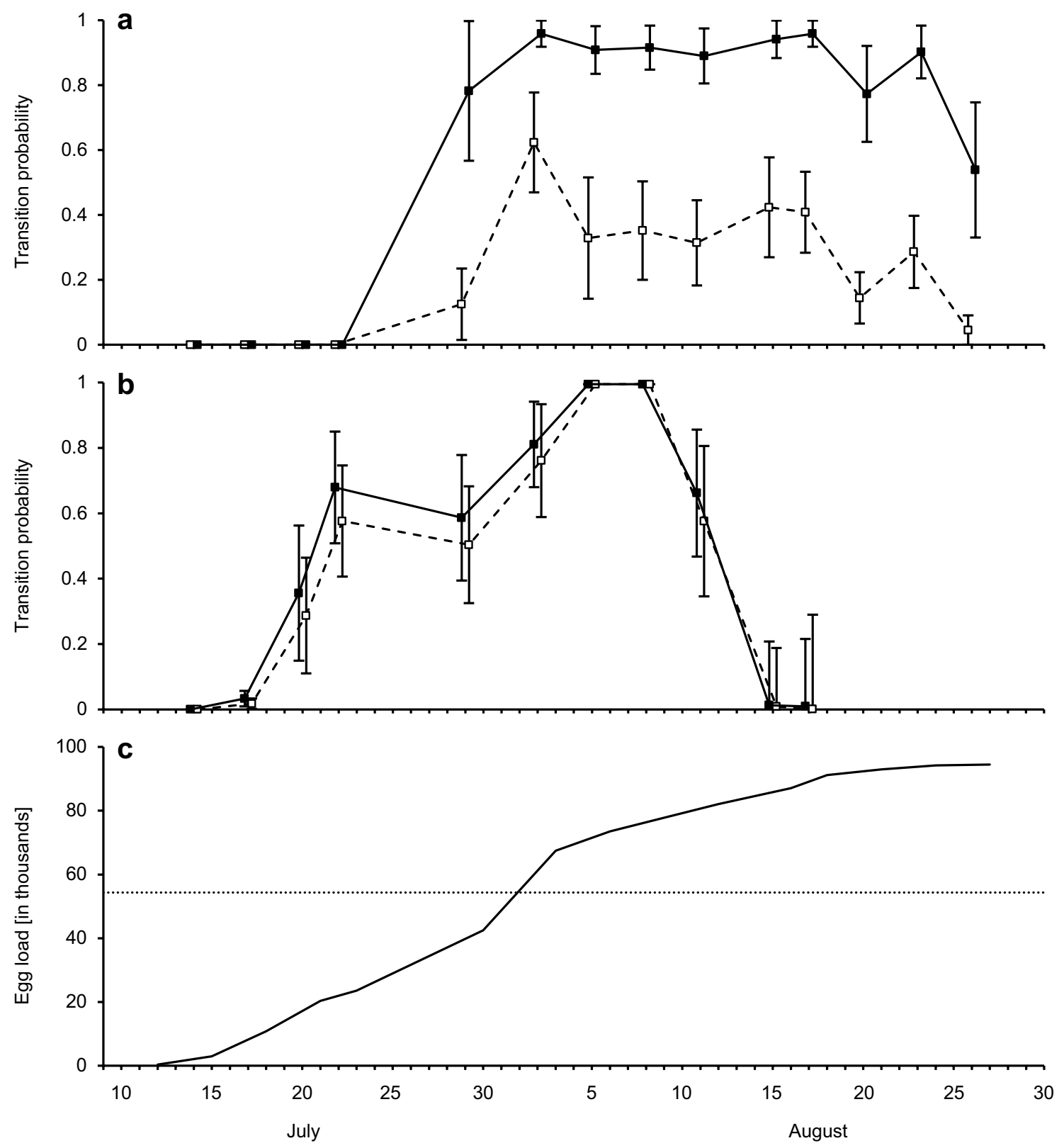

Fig. 3 Within-season dynamics of movements of M. nausithous (a) and M. teleius (b) from the central part to marginal fragments of the studied site, expressed with multi-state recapture model estimates of transition probabilities $( \pm S E)$ for both sexes (males: empty squares, broken line; females: solid squares, solid line). It should be noted that for the sake of consistency with the standard multi-state model notation, transition probabilities in each case are presented for the last day of the period between consecutive capture days, but they refer to the

patch centre to its margin coincided well with the period when egg load within the former area approached and exceeded the $S$. officinalis flowerhead availability. At the end of season the transition probabilities dropped again (except for $M$. nausithous females), but it should be underlined that these estimates referred to very small numbers of individuals still flying then. entire preceding period, starting from the previous capture day. The bottom panel (c) shows the dynamics of the number of Maculinea eggs oviposited within the central part of the site (solid line), assessed on the basis of the total number of both species' females present there prior to the date and average fecundity of 75 eggs per female (see the "Analysis" section of the text for rationale). The carrying capacity (dotted line) assumed as one-third of $S$. officinalis flowerheads available within this area is also shown for comparison

\section{Discussion}

M. nausithous and M. teleius often coexist (Sliwinska et al. 2006; Dierks and Fischer 2009; Nowicki et al. 2014), but the situation that they use the same host ant at a single locality is very infrequent (cf. Witek et al. 2008). The implication is that they are forced to utilise exactly the same limited 
resources at Fanatul Domnesc. Therefore, our results indicating that M. nausithous is about four times more abundant than M. teleius suggest that the former species is apparently more efficient in using the resources. The most likely explanation of the fact is its more efficient parasitic strategy. Inside ant nests Maculinea larvae either prey on ant brood ('predatory strategy') or are fed by ant workers ('cuckoo strategy'), with the latter strategy resulting in their higher survival (Thomas and Wardlaw 1992; Thomas and Elmes 1998). While $M$. teleius follows a strictly predatory strategy, M. nausithous shows the characteristics of both strategies (Thomas and Elmes 1998).

More importantly, our findings showed that a prevailing majority (ca. $80 \%$ ) of adult individuals in both investigated species eclosed within the relatively small central part of Fanatul Domnesc (ca. $15 \%$ of the total area of the site). We also demonstrated that with the flight period progression the butterflies gradually spread from the site centre to its peripheral fragments. This spreading was female-biased and its timing coincided well with the period when most of $S$. officinalis flowerheads present in the patch centre were likely to already contain Maculinea eggs. Females in several butterfly species, including Maculinea, were found to prefer foodplants without previously oviposited eggs in order to minimise intra-specific competition (in our specific case of M. nausithous and $M$. teleius potentially also interspecific one) experienced by their larval offsprings (Rausher 1979; Jones 1991; Dempster 1992; Van Dyck et al. 2000). Therefore, it may be expected that in order to find vacant flowerheads, female individuals eclosing in the patch centre are inclined to move towards outer fragments of the site in the second half of the season. Many males are likely to follow them when searching for mating partners (cf. Nowicki and Vrabec 2011).

While $S$. officinalis foodplants are similarly abundant in the peripheral fragments of Fanatul Domnesc, host ant colonies are relatively scarce there, and thus Maculinea larvae have little chance to be adopted by ants after they finish their initial development on foodplants. Consequently, these outer fragments apparently constitute sink areas with population growth rate well below one, and absorbing the excess individuals from the site centre. Obviously, in order to confirm source-sink dynamics in our study system the data spanning several years would be required (cf. Dias 1996). Regretfully, the data we have gathered in other years through non-intensive monitoring of the Fanatul Domnesc populations are not comprehensive enough so as to allow repeating the analyses conducted for 2010 . However, they clearly indicate a similar pattern, i.e. in July butterflies of both species were captured almost exclusively in the central fragment, whereas in August they were fairly evenly distributed between the two parts of the site (authors' unpubl. data).

The results we have obtained are in sharp contrast with several earlier studies on Maculinea, which found that edge fragments of habitat patches are typically of better quality and preferred by adult butterflies (Batáry et al. 2009; Körösi et al. 2012; Nowicki et al. 2013). The higher densities of host ant colonies due to their influx from surrounding areas free from the parasitic pressure by Maculinea were suggested as a potential explanation for such a pattern (Nowicki et al. 2007, 2013). Nevertheless, this explanation is reasonable for relatively homogeneous habitat patches, with different fragments being equally suitable for host ant colonies. At our clearly heterogeneous study site the ant community composition appears to be driven primarily by microhabitat conditions, which in turn are shaped by topography. The abundance of My. scabrinodis is relatively high only within the humid central part of the meadow, while in the drier peripheral fragments this host ant is partly outcompeted by other Myrmica species (Czekes 2012). Our findings thus imply that higher host ant availability at patch margins should not be regarded as a general rule applicable for any Maculinea site. Instead, local knowledge must be used in conservation actions, especially in setting management plans for different land fragments.

In the case of the Fanatul Domnesc site, its central part constituting the source area is undoubtedly crucial for the preservation of the local populations of M. nausithous and M. teleius. Moreover, it may be important for the persistence of both species in a wider region, since their populations at Fanatul Domnesc are the largest known in the region (authors' unpubl. data). Conservation efforts should thus be focused on maintaining the core area of Fanatul Domnesc in its present state, which is apparently near optimal for the focal species, since it supports relatively high densities of M. nausithous and moderate densities of M. teleius (compare Nowicki et al. 2007, 2014). This aim can presumably be achieved by the continuation of the current management regime, namely irregular mowing combined with extensive grazing (Stoianov et al. 2012).

The peripheral fragments of Fanatul Domnesc, representing sink areas, have lower conservation value. Nevertheless, it does not mean that they are of no importance for the persistence of the focal populations. As mentioned in the Introduction, it is often claimed that true sink areas are not helpful for preserving species of conservation concern, and they may even have a detrimental effect through 'sucking out' individuals from source areas and thus decreasing the overall population growth rate (Delibes et al. 2001; Robertson and Hutto 2006). However, this is not the case in our study system. If too many Maculinea larvae get into a single host colony, then they overexploit it (Thomas and Wardlaw 1992). Subsequently, they suffer from low survival and in the extreme case they may all die. This scramble competition among larvae leads to an increased level of population fluctuations (Thomas et al. 1998a). Therefore, by absorbing the excess individuals from the central source the peripheral 
sink fragments may reduce the extent of larval competition within the former area. In this way, they stabilise the entire population and enhance its long-term persistence.

One could argue that in the absence of sink fragments within the patch, population fluctuations could instead be buffered by the emigration of excess individuals. Positive density-dependence of emigration has indeed been reported for Maculinea butterflies (Nowicki and Vrabec 2011). Nevertheless, 'internal emigration' in the form of moving to peripheral sink areas is definitely more beneficial for the demography of the focal populations. Although, the reproductive success within the sink areas is low, it is still above zero and thus the butterflies eclosing in these areas increase the effective population sizes of both species. In fact, it is even possible that the site peripheries act as pseudo-sinks (sensu Watkinson and Sutherland 1995), i.e. they alone may be able to support small but still viable populations. On the other hand, genuine emigrants could enhance the persistence of further populations in the region, but such a possibility seems remote. This is because in reality few emigrants become immigrants elsewhere due to dispersal mortality, which is particularly high if the natal site is highly isolated and/or surrounded by inhospitable matrix (Bonelli et al. 2013; Nowicki et al. 2014). Especially the former problem is definitely true for Fanatul Domnesc.

All concerned, the existence of sink fragments surrounding the central source area improve the situation of both Maculinea species at Fanatul Domnesc. Nevertheless, they could benefit the focal populations far more, if it was possible to increase the reproductive success of the butterflies laying their eggs within these peripheral fragments through improved habitat quality. Our results imply that the availability of My. scabrinodis host ants is the limiting resource. Myrmica communities are determined by microhabitat conditions, deriving primarily from topography (Elmes et al. 1998). Obviously, the topography of our study site cannot be changed, but microhabitat conditions of meadow habitats are also dependent on turf height. Higher turf provides cooler and more humid conditions in the upper soil layers inhabited by ants (Elmes et al. 1998; Thomas et al. 1998b), thus favouring the colonies of My. scabrinodis. Therefore, reduced intensity of mowing and grazing should be recommended for the peripheral fragments of Fanatul Domnesc in order to allow higher vegetation growth there.

Acknowledgments The analysis was funded by the Polish National Science Centre through its grant DEC-2013/11/B/NZ8/00912. Christine Richards improved the English of the manuscript.

Open Access This article is distributed under the terms of the Creative Commons Attribution 4.0 International License (http://creativecommons.org/licenses/by/4.0/), which permits unrestricted use, distribution, and reproduction in any medium, provided you give appropriate credit to the original author(s) and the source, provide a link to the Creative Commons license, and indicate if changes were made.

\section{References}

Akaike H (1973) Information theory and an extension of the maximum likelihood principle. In: Petrov BN, Csaki F (eds) Second international symposium on information theory. Akademiai Kiado, Budapest, pp 267-281

Batáry P, Körösi A, Örvössy N, Köver S, Peregovits L (2009) Species-specific distribution of two sympatric Maculinea butterflies across different meadow edges. J Insect Conserv 13:223-230

Battin J (2004) When good animals love bad habitats: ecological traps and the conservation of animal populations. Conserv Biol 18:1482-1491

Bonelli S, Vrabec V, Witek M, Barbero F, Patricelli D, Nowicki P (2013) Selection on dispersal in isolated butterfly metapopulations. Popul Ecol 55:469-478

Boughton DA (1999) Empirical evidence for complex source-sink dynamics with alternative states in a butterfly metapopulation. Ecology 80:2727-2739

Brownie C, Hines JE, Nichols JD, Pollock KH, Hestbeck JB (1993) Capture-recapture studies for multiple strata including non-Markovian transitions. Biometrics 49:1173-1187

Burnham KP, Anderson DR (2001) Model selection and multi-model inference: a practical information-theoretic approach. SpringerVerlag, New York

Czechowski W, Radchenko AG, Czechowska W, Vepsäläinen K (2012) The ants of Poland with reference to the myrmecofauna of Europe. Fauna Poloniae 4. Natura Optima Dux Foundation, Warsaw

Czekes Zs (2012) Host ant communities and oviposition strategies of myrmecophilic butterflies Maculinea alcon and M. 'rebeli' (Lepidoptera: Lycaenidae) in Transylvania, Romania. PhD Thesis. Babeș-Bolyai University, Cluj-Napoca, Romania

Czekes Zs, Radchenko AG, Csősz S, Szász-Len A, Benedek K, Markó B, Tăuşan I (2012) The genus Myrmica Latreille, 1804 (Hymenoptera: Formicidae) in Romania: distribution of species and key for their identification. Entomol Rom 17:29-50

Delibes M, Gaona P, Ferreras P (2001) Effects of an attractive sink leading into maladaptive habitat selection. Am Nat 158:277-285

Dempster JP (1992) Evidence of an oviposition-deterrency pheromone in the orange-tip butterfly Anthocharis cardamines (L.). Ecol Entomol 17:83-85

Dias PC (1996) Sources and sinks in population biology. Trend Ecol Evol 11:326-330

Dierks A, Fischer K (2009) Habitat requirements and niche selection of Maculinea nausithous and M. teleius (Lepidoptera: Lycaenidae) within a large sympatric metapopulation. Biodivers Conserv 18:3663-3676

Diffendorfer JE (1998) Testing models of source-sink dynamics and balanced dispersal. Oikos 81:417-433

Elmes GW, Thomas JA (1992) The complexity of species conservation: interactions between Maculinea butterflies and their ant hosts. Biodivers Conserv 1:155-169

Elmes GW, Thomas JA, Wardlaw JC, Hochberg ME, Clarke RT, Simcox DJ (1998) The ecology of Myrmica ants in relation to the conservation of Maculinea butterflies. J Insect Conserv 2:67-78

Figurny E, Woyciechowski M (1998) Flowerhead selection for oviposition by females of the sympatric butterfly species Maculinea teleius and M. nausithous (Lepidoptera: Lycaenidae). Entomol Gen 23:215-222 
Hanski I, Moilanen A, Gyllenberg M (1996) Minimum viable metapopulation size. Am Nat 147:527-541

Hochberg ME, Clarke RT, Elmes GW, Thomas JA (1994) Population dynamic consequences of direct and indirect interactions involving a large blue butterfly and its plant and red ant hosts. J Anim Ecol 63:375-391

Hurvich CM, Tsai C (1989) Regression and time series model selection in small samples. Biometrika 76:297-307

Jones RE (1991) Host location and oviposition on plants. In: Bailey WJ, Ridsdill-Smith J (eds) Reproductive behaviour of insects: individuals and populations. Chapman and Hall, London, pp 108-138

Kőrösi A, Örvössy N, Batáry P, Harnos A, Peregovits L (2012) Different habitat selection by two sympatric Maculinea butterflies at small spatial scale. Insect Conserv Divers 5:118-125

Maes D, van Dyck H (2005) Habitat quality and biodiversity indicator performances of a threatened butterfly versus a multispecies group for wet heathlands in Belgium. Biol Conserv 123:177-187

Munguira ML, Martin J (eds) (1999) Action plan for Maculinea butterflies in Europe. Nature and Environment No. 97. Council of Europe Publishing, Strasbourg

Nowicki P, Vrabec V (2011) Evidence for positive density-dependent emigration in butterfly metapopulations. Oecologia 167:657-665

Nowicki P, Pepkowska A, Kudlek J, Skórka P, Witek M, Settele J, Woyciechowski M (2007) From metapopulation theory to conservation recommendations: lessons from spatial occurrence and abundance patterns of Maculinea butterflies. Biol Conserv 140:119-129

Nowicki P, Settele J, Henry P-Y, Woyciechowski M (2008) Butterfly monitoring methods: the ideal and the real world. Isr J Ecol Evol 54:69-88

Nowicki P, Bonelli S, Barbero F, Balletto E (2009) Relative importance of density-dependent regulation and environmental stochasticity for butterfly population dynamics. Oecologia 161:227-239

Nowicki P, Halecki W, Kalarus K (2013) All natural habitat edges matter equally for endangered Maculinea butterflies. J Insect Conserv 17:139-146

Nowicki P, Vrabec V, Binzenhöfer B, Feil J, Zakšek B, Hovestadt T, Settele J (2014) Butterfly dispersal in inhospitable matrix: rare, risky, but long-distance. Landscape Ecol 29:401-412

Pulliam HR (1988) Sources, sinks, and population regulation. Am Nat 132:652-661

Pulliam HR, Danielson BJ (1991) Sources, sinks, and habitat selection: a landscape perspective on population dynamics. Am Nat 137:S50-S66

Radchenko AGG, Elmes GWW (2010) Myrmica ants (Hymenoptera: Formicidae) of the Old World. Natura Optima Dux Foundation, Warsaw

Rákosy L, Tartally A, Goia M, Mihali C, Varga Z (2010) The Dusky Large Blue-Maculinea nausithous (Bergsträsser 1779) in the Transylvanian basin: new data on taxonomy and ecology. Nota Lepid 33:31-37

Rausher MD (1979) Egg recognition: its advantage to a butterfly. Anim Behav 27:1034-1040

Robertson BA, Hutto RL (2006) A framework for understanding ecological traps and an evaluation of existing evidence. Ecology $87: 1075-1085$

Runge JP, Runge MC, Nichols JD (2006) The role of local populations within a landscape context: defining and classifying sources and sinks. Am Nat 167:925-938

Settele J, Kuhn E, Thomas JA (eds) (2005) Studies in the ecology and conservation of butterflies in Europe. Vol 2. Species ecology along a European gradient: Maculinea butterflies as a model. Pensoft Publishers, Sofia
Sliwinska EB, Nowicki P, Nash DR, Witek M, Settele J, Woyciechowski M (2006) Morphology of caterpillars and pupae of European Maculinea species (Lepidoptera: Lycaenidae) with an identification table. Entomol Fenn 17:351-358

Stoianov E, Bărbos MI, Rus A, Paulini I (2012) Some population structure features and biometrical observations on Sanguisorba officinalis in Dabaca commune (Cluj County, Romania). Acta Horti Bot Bucur 39:43-51

Tartally A, Varga Z (2008) Host ant use of Maculinea teleius in the Carpathian-Basin (Lepidoptera: Lycaenidae). Acta Zool Acad Sci Hung 54:257-268

Tartally A, Rákosy L, Vizauer TC, Goia M, Varga Z (2008) Maculinea nausithous exploits Myrmica scabrinodis in Transylvania: unusual host ant species of a myrmecophilous butterfly in an isolated region (Lepidoptera: Lycaenidae; Hymenoptera: Formicidae). Sociobiology 51:373-380

Thomas JA (1995) The ecology and conservation of Maculinea arion and other European species of Large Blue Butterfly. In: Pullin AS (ed) Ecology and conservation of butterflies. Chapman and Hall, London, pp 180-197

Thomas JA, Elmes GW (1998) Higher productivity at the cost of increased host-specificity when Maculinea butterfly larvae exploit ant colonies through trophallaxis rather than by predation. Ecol Entomol 2:457-464

Thomas JA, Wardlaw JC (1992) The capacity of a Myrmica ant nest to support a predacious species of Maculinea butterfly. Oecologia 91:101-109

Thomas CD, Singer MC, Boughton DA (1996) Catastrophic extinction of population sources in a butterfly metapopulation. Am Nat 148:957-975

Thomas JA, Clarke RT, Elmes GW, Hochberg ME (1998a) Population dynamics in the genus Maculinea (Lepidoptera: Lycaenidae). In: Dempster JP, McLean IFG (eds) Insect population dynamics in theory and practice. Symposia of the Royal Entomological Society 19. Chapman and Hall, London, pp 261-290

Thomas JA, Simcox DJ, Wardlaw JC, Elmes GW, Hochberg ME, Clarke RT (1998b) Effects of latitude, altitude and climate on the habitat and conservation of the endangered butterfly Maculinea arion and its Myrmica ant hosts. J Insect Conserv 2:39-46

Tittler R, Fahrig L, Villard MA (2006) Evidence of large-scale sourcesink dynamics and long-distance dispersal among wood thrush populations. Ecology 87:3029-3036

Van Dyck H, Talloen W, Oostermeijer JGB, Feenstra V, Van der Hidde A, Wynhoff I (2000) Does the presence of ant nests matter for oviposition to a specialized myrmecophilous Maculinea butterfly? Proc R Soc Lond B 267:861-866

Vodă R, Timuş N, Paulini I, Popa R, Mihali C, Crişan A, Rákosy L (2010) Demographic parameters of two sympatric Maculinea species in a Romanian site (Lepidoptera: Lycaenidae). Entomol Rom 15:25-32

Watkinson AR, Sutherland WJ (1995) Sources, sinks and pseudosinks. J Anim Ecol 64:126-130

White GC, Burnham KP (1999) Program MARK: survival estimation from populations of marked animals. Bird Study 46:120-138

Witek M, Sliwinska E, Skórka P, Nowicki P, Wantuch M, Vrabec V, Settele J, Woyciechowski M (2008) Host ant specificity of large blue butterflies Phengaris (Maculinea) (Lepidoptera: Lycaenidae) inhabiting humid grasslands in East-central Europe. Eur J Entomol 105:871-877

Witek M, Nowicki P, Sliwinska E, Skórka P, Settele J, Schönrogge K, Woyciechowski M. (2010) Local host ant specificity of Phengaris (Maculinea) teleius butterfly, an obligatory social parasite of Myrmica ants. Ecol Entomol 35:557-564 